TEMPUS Revista en Historia General Medellín (Colombia), 2017, Segundo Semestre, Número 6 Pp. 140-173, ISSN: 2422-2178 (En línea)

\title{
PARAGUAY DESDE LA DICTADURA DE STROESSNER HASTA LAS ELECCIONES PRESIDENCIALES DE 2013
}

Fernando Fernández Palacios ${ }^{1}$

Universidad Complutense de Madrid DOI: 10.17533/udea.tempus.n6a06

\section{Resumen}

El artículo hace un recorrido por la historia de Paraguay en los últimos sesenta años, desde el golpe de Stroessner de 1954 hasta las elecciones presidenciales de 2013, tiempo durante el cual el país abandonó la dependencia económica argentina (en última instancia, la británica) y basculó hacia Brasil, que es el principal aliado que Estados Unidos de América tiene en la zona, país que por su parte ha establecido asimismo y de forma directa sólidas redes económicas en el propio Paraguay a través de algunas multinacionales.

Palabras clave: Paraguay, Dependencia, Estados Unidos de América, Argentina, Brasil, Reino Unido, economía, política.

\begin{abstract}
In the article we walk through the history of Paraguay of the last sixty years, from the Stroessner's coup d'état until the presidential elections of 2013, period during which the country left the Argentina's economic dependence (ultimately, the British one) and tipped the balance in the favour of Brazil, which is the main ally of the United States of America in the zone, country this last one that for its part has established straightforwardly strong economic networks in Paraguay through several multinationals.
\end{abstract}

Keywords: Paraguay, Dependence, United States of America, Argentina, Brazil, United Kingdom, Economics, Politics.

\section{Introducción.}

Paraguay ha sido un país celoso de su independencia y con unos habitantes que poseen un fuerte sentido de nacionalidad desde que un Congreso reunido en Asunción proclamó la república el 12 de octubre de 1813, algo que se promovió en tiempos de la dictadura de José Gaspar Rodríguez de Francia (1814-1840), un personaje que, a imitación de

\footnotetext{
${ }^{1}$ Doctor en Geografía e Historia, Universidad Complutense de Madrid, España. mbuchanscot@gmail.com.
} 
Napoleón, fue cónsul y emperador ${ }^{2}$. En este sentido, ni el caudillismo ni la anarquía política e institucional impidieron la pronta maduración del Estado, maduración ejemplificada en la Constitución de 1870. Económicamente, Paraguay fue desde entonces un ejemplo típico del modelo primario exportador que favoreció a puntuales oligarquías que resistieron crisis como la de fines del siglo XIX y la de $1929^{3}$. No obstante, por toda una serie de factores en los que no podemos detenernos ${ }^{4}$, el proceso de industrialización que economías como Argentina, México, Chile y Colombia vivieron entre la década de los 30 del siglo XX y la crisis de la deuda externa a principios de los 80 -el llamado modelo de industrialización por sustitución de importaciones ${ }^{5}$ - pasó de puntillas por Paraguay al igual que lo hizo por los países de América Central, acabando por abrazar, aunque un poco más tarde que otros Estados, el modelo del consenso de Washington, es decir, el "modelo neoliberal" basado en instituciones como el Fondo Monetario Internacional y el Banco Mundial, que han actuado liberalizando el comercio y las finanzas, desregulando los mercados de bienes y servicios ${ }^{6}$ e impulsando procesos de integración regional -en marcha desde mediados del siglo XX--, así UNASUR (Unión de Naciones Suramericanas), MERCOSUR (Mercado Común del Sur) y CELAC (Comunidad de Estados Latinoamericanos y Caribeños), en un mundo cada vez más globalizado.

A continuación, como antecedente del período que nos ocupa, aparecerá esbozado cómo Paraguay fue prácticamente una moneda de cambio en las relaciones

\footnotetext{
${ }^{2}$ Th. Whigham, hablando de la guerra de la Triple Alianza (1864-1870), destacaba cómo Paraguay “merced a la acción del Estado y fundado en un sistema de conscripción casi universal, había generado un sentimiento de nacionalidad único en el contexto platense que explicaría, además, la tenaz resistencia de la población paraguaya". Pablo Buchbinder, "Gente decente y "paysanos" contra la guerra: dimensiones de la resistencia a la Triple Alianza en la provincia de Corrientes", Iberoamericana. América Latina-EspañaPortugal 12, no. 47 (2012): 46.

${ }^{3}$ Dicho modelo se basaba en que el crecimiento de la renta dependía básicamente de la exportación de materias primas para atender la demanda en expansión de los países desarrollados, supeditándose la generación de riqueza al crecimiento económico de dichos países (europeos y EUA, principalmente).

${ }^{4}$ Ahí está por ejemplo, la Guerra del Chaco, que enfrentó a Paraguay y Bolivia, la cual duró de 1932 a 1935, y los diecinueve años siguientes (hasta el advenimiento de Stroessner), en que hubo tres golpes militares y trece presidentes, especialmente los momentos finales de los años 30, cuando grupos militares "influenciados por el nacionalismo y las doctrinas totalitarias de la Europa de entonces" lograron imponer "una Constitución corporativista en 1940" a la muerte del presidente Estigarribia. Por otro lado, la Juventud Obrera Cristiana de Paraguay se fundó en octubre de 1941 y fue la base de la formación de las Ligas Agrarias. Euclides Acevedo, "Aproximación a la realidad paraguaya: algunas ideas básicas para la transición", en Sistemas electorales y representación política en Latinoamérica. Vol. I, Ed, D. Koniecki (Madrid: Fundación Friedrich Ebert, 1986), 171.

${ }^{5}$ Cf. Santos M. Ruesga y Julimar da Silva Bichara, Modelos de desarrollo económico en América Latina: desequilibrio externo y concentración de riqueza (Madrid: Marcial Pons, 2005), 37.

${ }^{6}$ El Estado no crea ya mercado sino que lo desregula, como señaló Dionisio Borda, "Nuevas señales y viejos problemas", Economía y Sociedad (2013): 302.
} 
internacionales en la coyuntura de un Imperio británico en decadencia cuyas redes de poder fueron siendo adquiridas progresivamente por los Estados Unidos de América en el Cono Sur sobre todo desde los años 40 del siglo XX. La dependencia de Paraguay con respecto al Imperio Británico no se realizó casi nunca de manera directa sino a través del poder ejercido por Argentina en la zona. Sin embargo, desde finales de los años 40 la apuesta de los Estados Unidos de América por Brasil hizo que progresivamente Argentina fuera perdiendo importancia y Paraguay pasara a depender de los Estados Unidos de América por vía del dominio ejercido tanto directamente como por medio del propio país carioca.

\section{Antecedentes.}

Comenzamos por el año 1947. Un periodista de apenas 30 años llamado Augusto Roa Bastos llega como exiliado, huyendo de la persecución de Natalicio González, a una próspera Argentina bajo el gobierno de Juan Domingo Perón, que había accedido a la presidencia el año anterior ${ }^{7}$. Próspera Argentina pero bajo un régimen autoritario, producto de un pacto entre militares y sindicalistas, que había prohibido toda manifestación pública de partidos disidentes. En este contexto conviene recordar que la moneda paraguaya había dependido del peso argentino hasta bien entrada la década de $\operatorname{los} 40^{8}$ y que Chaves ya había establecido relaciones con Juan Perón siendo ministro de Exteriores, no obstante lo cual en la misma década Brasil aceptó las ofertas estadounidenses de ayuda militar y empezó a ofrecer becas para la formación de paraguayos en academias brasileñas hasta el punto que a mediados de la década mencionada el Jefe de Personal del Ejército paraguayo, coronel Rodrigo Díaz de Vivar, se había formado en Brasil, como habían hecho otros de igual trayectoria, entre ellos Stroessner (en 1940 y 1941, mandando en el país carioca Getúlio Vargas, iniciador del populismo en el Brasil $)^{9}$.

Entre 1946 y 1952 Paraguay recibió directamente de Estados Unidos de América 4,4 millones de dólares, a los que hay que sumar otros 4,6 millones a través de préstamos

\footnotetext{
${ }^{7}$ Los exiliados políticos paraguayos se dirigieron dentro de Argentina sobre todo a las ciudades de Buenos Aires, Córdoba y Posadas, y muchos de los que eligieron Brasil se establecieron en São Paulo. La época de auge de exilios transcurrió entre 1947 y 1950. Ver: José Luis Mora Mérida, Paraguay y Uruguay contemporáneos (Sevilla: Escuela de Estudios Hispano-Americanos de Sevilla, 1981), 68 - 132.

${ }^{8}$ Diego Abente, "Límites y posibilidades: perspectivas de la democratización en el Paraguay", Revista Paraguaya de Sociología no. 131 (2008): 12.

${ }^{9}$ Diego Abente, "Límites y posibilidades: perspectivas de la democratización en el Paraguay", 13-14.
} 
de organizaciones internacionales controladas por los EUA, lo que muestra bien a las claras la asistencia económica masiva de este país al Paraguay en los años anteriores a la llegada de Stroessner al poder ${ }^{10}$. Sin embargo, esta ayuda no se acompañó de estabilidad política: a pesar del populismo, entre 1947 y 1954 el Paraguay contó con siete presidentes. En agosto de 1953 Chaves accedió al poder de manera constitucional pero al cabo del tiempo sus medidas nacionalistas y reformistas no fueron del agrado de los Estados Unidos de América, que en el contexto de la Guerra Fría no quisieron ninguna veleidad en América del Sur y apoyaron a Stroessner a la vez que prosiguieron decididamente con la introducción de sus empresas en el funcionamiento económico paraguayo. Los tiempos eran difíciles. En Chile, por ejemplo, gobernó entre 1946 y 1952 Gabriel González Videla, que en un principio se apoyó en el Partido Radical y el Partido Comunista, pero a la altura de 1948 se había producido el alejamiento de los comunistas del gobierno y en las elecciones de 1952 subió al poder el general Carlos Ibáñez del Campo, que se mantendría en el puesto hasta $1958^{11}$.

El 26 de mayo de 1953, es decir un año antes del golpe definitivo de Stroessner en Paraguay, por Decreto n 14.966 se autorizó a dicha persona, por entonces General de División, a trasladarse a EUA para visitar dicho país y la zona del Canal "a los efectos de estrechar vínculos de amistad y solidaridad hemisférica" ${ }^{12}$. Fue invitado por Robert T. Stevens, Secretario del Ejército de los EUA, y por el general de brigada Emil C. Kiel, Comandante General de Aviación del Caribe.

\section{El golpe de Stroessner.}

En el contexto general esbozado anteriormente, el 8 de mayo de 1954 comenzó en Paraguay uno de los períodos más tristes de su historia con el derrocamiento del presidente Federico Chaves (1949-1954) mediante un golpe de Estado cuyo principal protagonismo correspondió a Alfredo Stroessner Matiauda (nacido en Encarnación en 1912), que había sido nombrado el 13 de octubre de 1951, con tan sólo 38 años de edad,

\footnotetext{
${ }^{10}$ A partir de 1946 los países sudamericanos empezaron a recibir de EUA armas, municiones, aviones y navíos sobrantes de la II Guerra Mundial. Murilo Melo Filho, El desafio brasileño (Buenos Aires: Pomaire, 1972), 161-162.

11 Anibal Miranda (Comp.), Documentos de Fuentes Norteamericanas: EE.UU. y el Régimen Militar Paraguayo (Asunción: El Lector, 1987).

12 Cf. Ernesto Moreno Beauchemin, Historia del movimiento sindical chileno. Una visión cristiana. Santiago de Chile (Santiago de Chile: ICHEH, 1986), 84-85. http://www.portalguarani.com/autores_detalles.php?id=1759, consultado el 22 de enero de 2013.
} 
comandante en jefe de las Fuerzas Armadas ${ }^{13}$. Culminaba así un movimiento promovido por el Partido Colorado desde 1947 (la llamada Revolución de ese año que acabó convirtiéndose en una guerra civil de seis meses de duración ${ }^{14}$ ) cuyo resultado fue que dicho partido pasó a ser el único legal en Paraguay hasta $1962^{15}$. Con la doctrina de contención en marcha, el presidente de los Estados Unidos de América, Truman, apoyó a los colorados recién aupados al poder y les ofreció ayuda económica ${ }^{16}$.

Entre el golpe de Estado de mayo de 1954 y agosto del mismo año el mando en Paraguay recayó en Tomás Romero Pereira en calidad de presidente interino, quien era además el máximo representante del Partido Colorado, y finalmente el 15 del último mes citado entregó el poder al coronel Stroessner después de unas elecciones en las que éste recibió el voto de unas 300.000 personas. En el intervalo del traspaso de poderes entre Tomás Romero Pereira y Alfredo Stroessner estuvo de visita en Paraguay (13-16 de agosto) Juan Domingo Perón, presidente de Argentina, quien asistió a la asunción del mando por parte de Stroessner, pronunciando incluso unas palabras en el Estadio del Club Cerro Porteño ${ }^{17}$. Era el canto del cisne de la primacía argentina sobre Paraguay. Por su parte, Stroessner ya era, por fin, caudillo, general y presidente. El 28 de junio de 1954, en una visita a Fort Sill (Oklahoma, EUA) -centro de artillería de campaña-, el Mayor General A. M. Harner otorgó a Stroessner el diploma de "Caballero de la Orden de Santa Bárbara" y el mismo día, en su visita a las unidades militares de los EUA en la zona central del Canal de Panamá, recibió la "Orden Eloy Alfaro”.

\footnotetext{
${ }^{13}$ Stroessner había ingresado en el ejército el 1 de marzo de 1929 como Cadete Efectivo de la Escuela Militar de la República, eligiendo como arma la Artillería, y había participado desde 1948 en cinco operaciones similares a la del triunfal golpe del 4 de mayo de 1954. Carlos María Lezcano, "El régimen militar de Alfredo Stroessner. Fuerzas Armadas y política en el Paraguay 1954-1989", Sintesis no. 10 (1990): 170.

${ }^{14}$ Cf. Alcibíades González del Valle, El Drama del 47: Documentos Secretos de la Guerra Civil (Asunción: El Lector, 1987). Fue una época en la que se quiso abrir el debate sobre el problema del reparto de tierras, así Pastore 1949, y en el que se publicaron en el extranjero, fruto muchas veces del exilio después del golpe de Estado, obras que pretendieron mostrar la riqueza artística y literaria de Paraguay: Juan Giuria, La arquitectura en el Paraguay (Buenos Aires: Instituto de Arte Americano e Investigaciones Estéticas, 1950); Walter Wey, La poesía paraguaya. Historia de una incógnita (Montevideo: Alfar, 1951). Políticamente, en 1951 se fundó en Buenos Aires el Partido Revolucionario Febrerista.

${ }^{15}$ Supuso la emigración de un $25 \%$ de la población, la práctica destrucción de la clase media y, como consecuencia, el desmoronamiento en el consumo de las artes. Esteban Bedoya, "La literatura paraguaya, de la dictadura hasta hoy", en Crónicas y ensayos paraguayos de ayer y hoy, tomo I, (Coord.) Teresa Méndez-Faith (Asunción: Intercontinental, 2009), 141.

${ }^{16}$ Diego Abente, "Límites y posibilidades: perspectivas de la democratización en el Paraguay", 19.

${ }^{17}$ Véanse en Secretaría de Prensa y Difusión 1954 los actos a los que asistió Perón durante su estancia en Paraguay.
} 


\section{Paraguay bajo Stroessner.}

Stroessner estuvo al frente de los destinos del país desde 1954 hasta 1989, sometiendo al Paraguay a una dictadura de 34 años de duración. En la época del estronismo R. A. Nickson ha distinguido las siguientes fases: de consolidación (19541967), de expansión (1968-1981) y de descomposición (1982-1989) ${ }^{18}$. Vamos con ellas.

El 11 de agosto de 1954 se publicó un documento en el cual el Partido Colorado mostraba posicionarse democrática, nacionalista y americanísticamente (sic) contra la intervención del comunismo internacional ${ }^{19}$. El primer embajador acreditado ante el nuevo gobierno de Stroessner fue el contralmirante estadounidense Arthur Ageton (9 de septiembre de 1954), y a continuación el 16 del mismo mes visitó Paraguay el secretario asistente para asuntos interamericanos de los EUA, Henry F. Holland, visitas estadounidenses que continuarían hasta diciembre ${ }^{20}$. Las atenciones de EUA para con el dictador paraguayo a partir de entonces se simbolizan en gestos como los siguientes: pocos años después del golpe el Comandante de la Primera División Blindada de los EUA distinguió en Fort Hood a Stroessner con la "Insignia de la División"; el 24 de junio de 1964 el dictador paraguayo recibió el "Pergamino de la Amistad" de Miami en consideración, se dijo, a su continuo servicio en nombre de la amistad, confraternidad y fortalecimiento de la causa de la libertad y la justicia de todos los pueblos, o la ciudadanía honoraria de Fulleton (California, EUA) otorgada al dictador paraguayo en noviembre de 1979.

En el año 0 del mando de Stroessner la Asociación Nacional Republicana (Partido Colorado) tenía las siguientes tendencias: los Guiones Rojos (la más nacionalista), los democráticos (liderados por el ex presidente Chaves y con muchos leales en la Junta de Gobierno), y los méndez-fleitistas, escisión de los democráticos e influidos por el peronismo argentino. Stroessner retuvo al más cercano aliado de Perón en Paraguay, el político colorado Epifanio Méndez Fleitas, en el cargo de Presidente del Banco Central

\footnotetext{
18 Robert Andrew Nickson, "El régimen de Stroessner (1954-1989)", en Historia del Paraguay, (Ed.) Ignacio Telesca (Asunción: Taurus, 2010), 265-94.

19 Alfredo Stroessner, El Coloradismo Paraguayo frente a la Organización Comunista Internacional (Asunción: Imprenta Nacional, 1954). El Partido Comunista Paraguayo, adherido al Kominform en 1947, se había aliado con el Partido Febrerista en la lucha por derrocar al general Morínigo en el año mencionado. José Luis Mora Mérida, Paraguay y Uruguay contemporáneos (Sevilla: Escuela de Estudios HispanoAmericanos de Sevilla, 1981), 66-67.

${ }^{20}$ Carlos María Lezcano, "El régimen militar de Alfredo Stroessner. Fuerzas Armadas y política en el Paraguay 1954-1989”, Síntesis no. 10 (1990): 170-171.
} 
pero después de la caída de Perón en septiembre de 1955, apenas dos meses después Fleitas renunció a su cargo y marchó al exilio a inicios de $1956^{21}$. El régimen de Stroessner, por su parte, ofreció asilo a Perón, quien se instaló primero en un buque de guerra paraguayo y después marchó por vía aérea a Asunción ${ }^{22}$.

El año 1955 se inició con un Estado de Sitio, produciéndose purgas en el Partido Colorado y en las Fuerzas Armadas. El 17 de octubre de 1955 se institucionalizó la dictadura con la ley 294 de Defensa de la Democracia, que permitía acusar de comunista a cualquier opositor ${ }^{23}$, y las primeras grandes manifestaciones contra el régimen ocurrieron el 10 de abril de 1956. A pesar de todo, la dictadura siguió adelante. Su institucionalización se produjo teniendo el país una red de carreteras de tan sólo 3000 kilómetros, de los cuales únicamente 95 estaban asfaltados ${ }^{24}$, un país en el que, según el censo de aquel año, once haciendas del oriente del país disponían del $35 \%$ del total de área cultivada en Paraguay ${ }^{25}$.

En la fase de consolidación de Stroessner en el poder hay dos fechas especialmente importantes: 1958, debido a que fue entonces cuando la aceptación de un plan monetario de congelamiento salarial permitió que la ayuda financiera del Fondo Monetario Internacional empezara a llegar al país coincidiendo con la primera reelección de Stroessner, y 1959, año del triunfo de la revolución cubana y de la disolución del Parlamento y convocatoria de elecciones por parte del dictador.

Hemos mencionado la resistencia a la dictadura desde los inicios, y es que no conviene olvidar que en los primeros años del régimen de Stroessner hubo levantamientos populares, complots militares (organizados sobre todo en Argentina) y movimientos guerrilleros más adelante (en 1959 y 1960) ${ }^{26}$. Pero la dictadura llegaba a Paraguay en un momento en el que se cerraba en Hispanoamérica el ciclo de varios gobiernos populistas y dictaduras militares: Vargas en Brasil (1954), Perón en Argentina (1955), Rojas Pinilla

\footnotetext{
${ }^{21}$ Con él se fueron del país también muchos mandos militares y funcionarios gubernamentales.

22 Diego Abente, "Límites y posibilidades: perspectivas de la democratización en el Paraguay”, 15.

${ }^{23}$ Dicha ley, junto con la 209, invalidaron la mayor parte de los derechos políticos constitucionales. Euclides Acevedo, “Aproximación a la realidad paraguaya: algunas ideas básicas para la transición”, 174.

${ }^{24}$ José María García Alvarado y Javier Gutiérrez Puebla, Paraguay (Madrid: Anaya, 1989), 108.

${ }^{25}$ Enrique Ruiz García, América Latina, hoy. Anatomía de una revolución (Madrid: Alianza, 1971), 287.

${ }^{26}$ En 1959 el dictador consiguió desarmar y desmovilizar a las milicias coloradas y expulsar del partido al grupo que más adelante se conocería como Movimiento Popular Colorado. Carlos María Lezcano, "El régimen militar de Alfredo Stroessner...”, 173. Ese año los partidos Liberal y Revolucionario Febrerista firmaron en el exilio el Acuerdo para la Libertad.
} 
en Colombia (1957), Pérez Jiménez en Venezuela (1958) y Batista en Cuba (1959). ${ }^{27}$ El giro a la izquierda de Janio Quadros a partir de su toma de posesión como presidente de Brasil el 31 de enero de 1961 le trajo al país carioca un turbulento año en el que a la altura del 7 de septiembre ya habían pasado por el sillón presidencial cuatro personas ${ }^{28}$.

La consolidación de Stroessner se afianzó desde principios de los años 60 en el marco de la Doctrina de la Seguridad Nacional estadounidense, que favoreció la definitiva implantación de empresas estadounidenses en Paraguay, creándose el Atlantic Community Development Group for Latin America (ADELA), organismo nacido en 1963 para desarrollar la Alianza para el Progreso impulsada por Kennedy, es decir, el plan Marshall de Hispanoamérica, que fue decidido en la Conferencia de Punta del Este (Uruguay) de 1962 convocada por la OEA (Organización de Estados Americanos), plan que canalizó capital europeo, japonés y estadounidense para su inversión en la América hispana $^{29}$. A lo largo de esta fase de consolidación estuvo de visita oficial en Paraguay el duque de Edimburgo -del 9 al 12 de marzo de 1962-, y del 6 al 8 de octubre de 1964 el presidente de Francia, De Gaulle.

La distribución de la propiedad agrícola en Paraguay, en datos de 1961, era radicalmente grave. De 160.775 explotaciones, el $43 \%$ correspondía a propietarios, el 12 $\%$ a arrendatarios y el $45 \%$ a ocupantes precarios ${ }^{30}$. En 1963 se creó el Instituto de Bienestar Rural para que se ocupara de los asuntos de colonización y reforma agrarias ${ }^{31}$, pero fue aprovechado por miembros de la Asociación Rural del Paraguay (ARP) para hacerse con grandes extensiones de tierra de manera ilegítima ${ }^{32}$. En 1965 se puso en marcha el primer Plan Bienal de Desarrollo, coincidiendo con la ayuda paraguaya a la intervención militar estadounidense en la República Dominicana, y a la altura de 1968 se habían organizado, con la ayuda del Banco Interamericano de Desarrollo (BID), más de

\footnotetext{
${ }^{27}$ Cf. Jorge Graciarena y Rolando Franco, Formaciones sociales y estructuras de poder en América Latina (Madrid: Centro de Investigaciones Sociológicas, 1981), 73.

${ }^{28}$ Murilo Melo Filho, El desafío brasileño..., 7-8.

${ }^{29}$ Sobre la Conferencia de Punta del Este véase: Ann van Wynen Thomas y Archibald J. Thomas, Jr., La Organización de los Estados Americanos (México: 1968), 74-7 y 308-9. América Latina era considerada "the soft underbelly of the United States". Josef Kalvoda, "Communist Strategy in Latin America", The American Review no. 3 (1961): 6.

${ }^{30}$ José Luis Mora Mérida, Paraguay y Uruguay contemporáneos, 94. Todo ello producía precariedad, mera subsistencia, descapitalización y bajísima productividad. Enrique Ruiz García, América Latina, hoy. Anatomía de una revolución, 287-288.

${ }^{31} \mathrm{Su}$ antecesor fue el Instituto de Reforma Agraria, creado en 1950. En Chile, por ejemplo, se aplicó la ley de Reforma Agraria durante el mandato de Eduardo Frei (1964-1970).

${ }^{32}$ Tomas Palau, "Los actores del modelo: gremios y empresarios bien alineados", Acción no. 317 (2011): 16.
} 
200 colonias oficiales que afectaban a 231.127 habitantes, mientras que la colonización privada abarcaba, según algunos estudios, 80 establecimientos, en los que vivían más de 115.000 personas $^{33}$. Hubo casos en que la policía intervino para que los colonos no salieran huyendo de sus nuevos territorios asignados ${ }^{34}$.

Culturalmente, en la década de los 60 se gestó en Paraguay una nueva generación de artistas y escritores que constituyeron una cultura marginal, sin apenas lazos con el sistema oficial, marginalidad cultivada en cineclubes, grupos de teatro independiente, etc ${ }^{35}$. Literariamente, hubo una dispersa generación del 60 que pudo publicar algunos textos y realizar varias reuniones.

En 1965 se inauguró (tras el acto simbólico realizado por Stroessner y Kubitschek cuatro años atrás, el 27 de enero de 1961) el Puente de la Amistad sobre el río Paraná, que pone en contacto estrecho las localidades de Ciudad del Este (Paraguay) y Foz de Yguazú (Brasil), por el que actualmente pasan unas 25.000 personas y más de 10.000 vehículos $^{36}$, puente que en definitiva une Asunción con São Paulo. Para Brasil la ruta 277, que une Asunción y Paranaguá, sigue siendo de gran importancia para su seguridad nacional ${ }^{37}$. La inauguración de esta vía de comunicación fue el hecho definitivo que puso de relieve la dependencia paraguaya de Brasil.

En 1966 Stroessner convocó una Asamblea Constituyente de la que salió una nueva Constitución en 1967. La fase de expansión del estronismo, que comenzó en 1968 con la reelección del dictador ${ }^{38}$, tuvo como actividad inicial la invitación que el presidente

\footnotetext{
${ }^{33}$ José Luis Mora Mérida, Paraguay y Uruguay contemporáneos, 97-99. Los datos contrastan con Enrique Ruiz García, América Latina, hoy. Anatomía de una revolución, 292, quien señala que los programas de colonización parecían haber asentado a unas 6000 familias hasta 1968. Posteriormente, entre 1970 y 1982 se reasentó a 41.841 familias campesinas. Ramon Fogel, "Tierra y democracia. La lucha de los campesinos paraguayos", Síntesis no. 10 (1990): 277.

${ }^{34}$ Como señalaba Eduardo Galeano, el "plan oficial de colonización en el triángulo de Caaguazú ofrece a los campesinos hambrientos más tumbas que prosperidades". Eduardo Galeano, Las venas abiertas de América Latina (Madrid: Siglo XXI, 1980), 323.

35 Antonio Pecci, "Apuntes acerca del exilio interior y la creciente producción cultural del país", en Crónicas y ensayos paraguayos de ayer y hoy, tomo II, (Coord.) Teresa Méndez-Faith (Asunción: Intercontinental, 2009), 625-626.

${ }^{36} \mathrm{http}: / /$ diarioprimeraplana.com/index.php?option=com_content $\&$ view=article \&id=1346:sombrioaspecto-presenta-el-puente-de-la-amistad-a-47-anos-de-su-inauguracion \&catid=37:locales \&Itemid=27, consultado el 22 de enero de 2013.

${ }^{37}$ Murilo Melo Filho, El desafío brasileño..., 165.

${ }^{38}$ A estas alturas había más de medio millón de paraguayos viviendo en Brasil, Uruguay y Argentina por motivos políticos y económicos, entre los que se encontraban no pocos individuos pertenecientes a las elites. Marcel Niedergang, Les 20 Amériques latines. 1. Brésil. Argentine. Uruguay. Paraguay (París: Editions du Seuil, 1969), 231.
} 
paraguayo recibió de su homólogo estadounidense, Lyndon B. Johnson, para que el 9 de marzo de dicho año, poco antes de las elecciones paraguayas, se trasladara a EUA acompañado de altos cargos civiles y militares, empresarios y periodistas, con el objetivo de llevar a cabo un apretado programa de actividades en Washington y Nueva York. Soplaban vientos de dictadura en la zona. Por ejemplo, Uruguay en 1966, merced al Partido Colorado, retornó a un poder unipersonal después de 13 años de régimen colegiado $^{39}$.

En los años 70, cuando en la Universidad paraguaya surgían estructuras como el Movimiento Independiente y el Movimiento por la Reagrupación Universitaria, algunos de los grandes negocios en Paraguay consistieron en la construcción de infraestructuras amparadas por el Ministerio de Obras Públicas y Comunicaciones en colaboración con los gremios empresariales con un coste desorbitante (ACEPAR, Inc., PETROPAR, Gran Hospital Nacional, etc. $)^{40}$. A pesar del escándalo del Gran Hospital Nacional, oficialmente todo eran beneficios por parte del Ministerio de Salud Pública y Bienestar ${ }^{41}$. Así las cosas Stroessner, una vez reelegido, estuvo del 20 al 23 de julio de 1973 de visita oficial en la República Federal de Alemania y del 9 al 12 de noviembre de dicho año vino a Paraguay Alfons Goppel, ministro presidente del Estado de Baviera y presidente del Bundesrat alemán. Asimismo, del 25 al 27 de julio Stroessner fue recibido en París por Georges Pompidou. La dictadura parecía gozar de buena salud y la coyuntura internacional no invitaba a ver un final cercano: en Chile se producía el golpe de Estado de Pinochet y en Uruguay el de Bordaberry.

Hacia mediados de los 70 Brasil sobrepasó a Argentina como principal socio comercial de Paraguay ${ }^{42}$. El Puente de la Amistad había dado sus buenos resultados para Brasil y los Estados Unidos de América. Entonces en Paraguay se rompió la tradicional relación entre campesinado, hacienda ganadera y latifundio maderero, y comenzaron los grandes desplazamientos migratorios hacia Asunción con el consiguiente desarraigo campesino. La preferencia comercial brasileña no era sino un síntoma, en definitiva, de la hegemonía estadounidense, y la postergación de Argentina mostraba a las claras la

\footnotetext{
${ }^{39}$ José María García Alvarado, Uruguay (Madrid: Alcalá, 1988), 43.

${ }^{40} \mathrm{http}$ ///www.pedrojuandigital.com/1785-v-nacionales2-u-.html, consultado el 5 de enero de 2013.

${ }^{41}$ Alfredo Stroessner, Mensaje del Excmo. Señor Presidente de la República y Comandante en Jefe de las Fuerzas Armadas de la Nación general de Ejército Alfredo Stroessner a los Honorables Miembros del Congreso Nacional (Asunción: Imprenta Nacional, 1973).

${ }^{42}$ Diego Abente, "Límites y posibilidades: perspectivas de la democratización en el Paraguay", 18.
} 
decadencia británica. En expresión de Eduardo Galeano, Paraguay padecía el imperialismo y el subimperialismo, y era colonia de colonias ${ }^{43}$.

En plena fase estroessneriana de consolidación, el 25 de noviembre de 1976 "nació" en Chile la Operación Cóndor, la cual organizó metódicamente la represión en Argentina, Bolivia, Brasil, Chile, Paraguay y Uruguay ${ }^{44}$. En 1977 se puso en marcha en Paraguay el Plan Nacional de Desarrollo, que duraría hasta 1981, y se declaró ilegal el Partido Liberal Unido. No es de extrañar, vistas las cosas, que a mediados de los 70 hubiera varios intentos de matar a Stroessner que contaron con el apoyo del Ejército Revolucionario del Pueblo ${ }^{45}$. El 6 de septiembre de 1977, año en el que hubo que hacer una enmienda constitucional para que el dictador pudiera ser reelegido de manera vitalicia, Stroessner fue recibido en la Casa Blanca por el presidente estadounidense Jimmy Carter, y la represión continuó firme con la suspensión el 18 de junio de 1979 de los diarios Última Hora y La Tribuna. En Brasil, el general Figueiredo unos meses después, mediante la ley de 29 de noviembre de 1979, creó un sistema multipartidista preservando las fuerzas del gobierno en un único partido ${ }^{46}$, algo que recuerda a lo que Stroessner había llevado a cabo una década antes.

En el ámbito cultural conviene destacar en 1976 la creación del centro cultural "Juan de Salazar" a cargo del Gobierno español:

"El más importante espacio de encuentro y convocatoria de escritores y poetas,
espectáculos de teatro, danza, conferencias y presentaciones de libros, dando un
singular empuje a la actividad cultural, con un claro enfoque
democratizador"

En 1980, año en el que la ley 832 actualizó la organización de las Fuerzas Armadas del país, se declaró el Estado de Sitio después del magnicidio del mandatario nicaragüense Somoza en territorio paraguayo y de un brote guerrillero que operó en Caaguazú.

Los años 80 comenzaron mal para el país. Con un $50 \%$ de la población que podía considerarse analfabeta funcional (un $27 \%$ lo era oficialmente), Paraguay cobró

\footnotetext{
${ }^{43}$ Eduardo Galeano, Las venas abiertas de América Latina, 320.

${ }^{44}$ Véase, por ejemplo, John Dinges, Operación Cóndor. Una década de terrorismo internacional en el Cono Sur (Santiago de Chile: Ediciones B, 2004), y para la importancia de Paraguay en su inicio consúltense especialmente las pp. 123-45.

45 John Dinges, Operación Cóndor..., 126-127.

${ }^{46}$ Leonardo Díaz, Lula (Barcelona: Folio, 2005), 43-44.

${ }^{47}$ Antonio Pecci, “Apuntes acerca del exilio interior y la creciente producción cultural del país”, 627.
} 
importancia internacional debido a ser un lugar clave en el tránsito de cocaína desde Bolivia a Estados Unidos de América y Europa, y como consecuencia de ello se importaron diversos productos químicos para refinar la droga. Además, el contrabando de productos electrónicos por la frontera brasileña alcanzó un gran volumen ${ }^{48}$. Según Eduardo Galeano, Stroessner declaró que el contrabando era “el precio de la paz", ya que así los generales se enriquecían y no conspiraban ${ }^{49}$. De esta manera se entró en la fase de descomposición del mandato de Stroessner. Mientras en el Brasil presidido por Figueiredo había elecciones generales el 15 de noviembre de $1982^{50}$, las cuales fueron las primeras multipartidistas desde $1964^{51}$, en Paraguay la crisis económica de 1982 -que duraría siete largos años- fue especialmente aguda, crisis agravada por la finalización de la construcción de la presa de Itaipú $(1972-1981)^{52}$ y la caída de los precios internacionales de la soja y el algodón ${ }^{53}$. A partir de 1982 asistimos de facto a una devaluación del guaraní.

Políticamente la ley electoral 886 de 1982 modificó la ley 600 de 1962 pero siguió asegurando el control del sistema político e incluso judicial a Stroessner. De esta manera, el 6 de febrero de 1983 se produjo la reelección del dictador con un $90 \%$ de los votos. Los cambios en el reparto de tierras habían ido a peor: en 1984 la FAO (Food and Agriculture Organization de las Naciones Unidas) indicaba que 25 grandes terratenientes, entre ellos varias empresas transnacionales, poseían el $32 \%$ del territorio paraguayo ${ }^{54}$. Los problemas del Paraguay llevaron a que el Movimiento Intersindical de Trabajadores (MIT) empezara a agrupar a sindicatos fuera de la órbita de la Confederación Paraguaya de Trabajadores (CPT), creada en 1939 y que estaba controlada por el gobierno. En 1985, aunque en Paraguay se reconocía constitucionalmente la libertad de convenio, ésta por supuesto no se aplicaba, y no existía fuero sindical ${ }^{55}$.

\footnotetext{
${ }^{48}$ El contrabando alcanzó niveles escandalosos entre 1973 y 1982.

${ }^{49}$ Eduardo Galeano, Las venas abiertas de América Latina, 322.

${ }^{50}$ Véase Riordan Roett, Brazil. Politics in a Patrimonial Society (Westport: Greenwood Publishing Group, 1992), 155.

${ }^{51}$ Leonardo Díaz, Lula, 50.

${ }^{52}$ La presa fue inaugurada oficialmente el 5 de noviembre de 1982 por Stroessner y el presidente de Brasil, João Baptista de Oliveira Figueiredo. El comienzo de su construcción había señalado de manera simbólica para muchos la aceleración de la destrucción del hábitat de las comunidades indígenas.

${ }^{53}$ En relación a 1980, el precio real de la soja en el mercado internacional cayó en 1986 un 39 \%, y el del algodón un 43 \%. Ramon Forgel, “Tierra y democracia. La lucha de los campesinos paraguayos", Síntesis no. 10 (1990): 279.

${ }^{54}$ Atilio Cazal, "Paraguay: un país hipotecado", Nueva Sociedad no. 73 (1984): 16.

55 Alberto Cuevas, Sindicato y poder en América latina. Modelos y tendencias del sindicalismo latinoamericano (Madrid: Alianza América, 1990), 55-6 y 63.
} 
En 1984, año de cierre del diario ABC Color, de la segunda devaluación del guaraní y de la caída de los jornales agrícolas en un 10 \% en relación a 1970, J. A. Cazal apuntaba que entre los militares que manejaba Estados Unidos de América para el posestronismo figuraba el general Andrés Rodríguez ${ }^{56}$. Los regímenes democráticos, aunque un tanto peculiares, eran los que entonces apoyaban los Estados Unidos de América en el Cono Sur (transiciones de Sanguinetti en Uruguay, Raúl Alfonsín en Argentina y José Sarney en Brasil).

En 1985 se cerró Radio Nandutí, se creó la Agrupación Independiente de Trabajadores (AIT) dentro del Movimiento Intersindical de Trabajadores (MIT) y Euclides Acevedo, ex presidente del Partido Revolucionario Febrerista, señaló que el contrabando abarcaba las $2 / 3$ partes del comercio exterior del país ${ }^{57}$. Curiosamente, fue hacia la mitad de los años 80 cuando algunos importantes fenómenos sociales como el feminismo empezaron a difundirse en Paraguay ${ }^{58}$. En 1986 se intentó atajar la crisis desde el sector público mediante un Plan de Impulso a la Economía que resultó ser prácticamente fantasma. Lo que se produjo fue la aparición en octubre de un tercer tipo de cambio oficial y, por consiguiente, una tercera devaluación del guaraní ${ }^{59}$.

La crisis definitiva del sistema se escenificó el 1 de agosto de 1987 cuando el Partido Colorado, en medio de una división entre tradicionalistas y militantes estronistas, vio cómo en la convención del partido se impidió que entraran los colorados tradicionalistas opositores (el llamado sector civil). Los altos cargos del partido estaban tan ocupados en sus querellas internas que no se daban cuenta de que el Acuerdo Nacional parecía imparable ${ }^{60}$. Stroessner se había quedado sin el apoyo estadounidense y

\footnotetext{
56 Quien como veremos acabó gobernando Paraguay entre 1989 y 1993 a pesar de las supuestas vinculaciones que le unían con el narcotráfico.

${ }^{57}$ Euclides Acevedo, “Aproximación a la realidad paraguaya: algunas ideas básicas para la transición”, 175.

${ }^{58}$ Cf. Clyde Soto, "Desafíos para el feminismo en Paraguay", en La mujer latinoamericana ante el reto del siglo XXI. IX Jornadas de Investigación Interdisciplinaria sobre la Mujer, Ed, Pilar Pérez Cantó y Marta Elena Casaús Arzú (Madrid: Universidad Autónoma de Madrid, Instituto Universitario de Estudios de la Mujer, 1993), 167-168.

59 Tomas Palau, "La difícil compatibilidad entre las tendencias del comercio exterior y la adecuación monetaria", Síntesis no. 10 (1990): 317-3188.

${ }^{60}$ El Acuerdo Nacional fue un documento que firmaron el 14 de abril de 1984 las siguientes fuerzas: el Partido Demócrata Cristiano (fundado en 1965), el Partido Liberal Radical Auténtico, el Partido Revolucionario Febrerista y el Movimiento Popular Colorado, y era una ampliación del programa de convergencia nacional de 14 puntos firmado por dichos partidos en febrero de 1979 (véase "Acuerdo Nacional", Revista Paraguaya de Sociología no. 131 (2008): 37-43.

Fuera del Acuerdo Nacional quedaron el Partido Comunista y la Organización Político-Militar Revolucionaria. Por otra parte, en 1981 se había producido el Acuerdo Paraguayo en el exilio, base del
} 
naufragaba en política exterior manteniendo disparatadas alianzas -tímidamente asentadas en los años 70- con países como Taiwán ${ }^{61}$, la Sudáfrica del apartheid $^{62}$, la Corea del Sur dictatorial ${ }^{63}$ y Japón ${ }^{64}$. En mayo de 1988 el papa Juan Pablo II visitó Paraguay ${ }^{65}$, y el 10 de diciembre de dicho año, día de los Derechos Humanos, las fuerzas contestatarias se lanzaron abiertamente a la calle.

\section{El derrocamiento de Stroessner.}

Siete reelecciones después (1958, 1963, 1968, 1973, 1978, 1983 y 1988), años que en ocasiones coincidieron con los de represiones preventivas por parte del Gobierno ${ }^{66}$, con un pluralismo político restringido desde 1962 merced a la ley $600^{67}$-ya que el régimen de Stroessner cuidó la coexistencia de estructuras legales-formales y sistemas patrimonialistas de distribución del poder político y económico ${ }^{68}$, en la noche del 2 de febrero de 1989 un golpe de Estado (el golpe de Estado de la Candelaria) dirigido por Andrés Rodríguez, consuegro de Stroessner, devolvió sangrientamente -sólo en Asunción hubo más de 200 muertos- la libertad a Paraguay y acabó con el férreo mando del dictador, aunque se le permitió marchar a un dorado exilio en Brasilia, de donde no

Movimiento Popular Colorado (MOPOCO), que hacia 1986 consiguió permiso para el retorno de sus principales dirigentes y que en 1989 se retiró del Acuerdo Nacional.

${ }^{61}$ Una década antes, concretamente el 21 de septiembre de 1975, Stroessner había sido recibido en Taipéi por Yen Chia Iban, presidente de Taiwán. Diego Abente, "Límites y posibilidades: perspectivas de la democratización en el Paraguay", 31, puntualiza que el apoyo de Taiwán se realizó sobre todo en los ámbitos político-militar y de inteligencia (con participación de la secta Moon en esta última actividad).

${ }^{62}$ Ya del 2 al 6 de abril de 1974 Stroessner se había entrevistado en Pretoria con el presidente sudafricano, Jocabo Johannes Fouché, y del 13 al 17 de agosto de 1975 había estado en Paraguay de visita oficial Balthazar Johannes Vorster, primer ministro sudafricano.

${ }^{63}$ José Félix Fernández Estigarribia, "Perspectiva de cambio de la política exterior paraguaya", Revista Paraguaya de Sociología no. 131 (2008): 183.

${ }^{64}$ Diego Abente, "Límites y posibilidades: perspectivas de la democratización en el Paraguay", 31, señala que Japón ofreció asistencia económica. El emperador Hirohito había invitado ya a Stroessner a una visita oficial que se desarrolló del 12 al 19 de abril de 1972. Con el gobierno de Japón se acordó el ingreso en Paraguay de 85.000 personas durante 30 años para que se establecieran en el Alto Paraná y otras partes. José Luis Mora Mérida, Paraguay y Uruguay contemporáneos, 100.

${ }^{65}$ La Conferencia Episcopal Paraguaya había mostrado su tibia postura con respecto al régimen en un mensaje sobre el Diálogo Nacional publicado el 20 de abril de 1986 (véase "Mensaje de la Conferencia Episcopal Paraguaya sobre el Diálogo Nacional", Revista Paraguaya de Sociología no. 131 (2008): 45-48. Anteriormente, en 1983, se había escrito una pastoral sobre el problema de la distribución de la tierra (Peasants \& Land. A pastoral letter from the bishops of Paraguay -Church in the World, 17, 1983-). Durante la dictadura, Stroessner llegó a visitar a Pablo VI en Castelgandolfo el 25 de julio de 1973.

${ }^{66} 1955,1958$ (reacción a la huelga general convocada por la Confederación Paraguaya de Trabajadores el 27 de agosto), 1961-2, 1965, 1972, 1974, 1976, 1981 y 1983. Euclides Acevedo, “Aproximación a la realidad paraguaya: algunas ideas básicas para la transición”, 174-175.

${ }^{67}$ Año de fundación de la Confederación Cristiana de Trabajadores, donde se incluyeron las Ligas Agrarias Cristianas, que tuvieron vigencia entre 1959 y 1976. José Carlos Rodríguez, "Sindicalismo y transición. Paraguay 1989”, Síntesis no. 10 (1990): 252 y 259.

${ }^{68}$ Carlos María Lezcano, "El régimen militar de Alfredo Stroessner. Fuerzas Armadas y política en el Paraguay 1954-1989”, Síntesis no. 10 (1990): 172. 
se le pudo traer a pesar del intento de extradición de 1995. Su hijo Gustavo, coronel de las Fuerzas Armadas, vivió también en Brasil a pesar de estar reclamado por la justicia paraguaya. El dictador Stroessner acabó muriendo el 16 de agosto de 2006 con 93 años de edad y legando a su familia se estima que más de 5.000 millones de dólares, principalmente en negocios de grandes navieras, fincas urbanas y rurales, y empresas.

Sin embargo, la caída del dictador no fue acompañada por un feliz regreso a la normalidad democrática. En la madrugada del día 3 de febrero de 1989 en la Radio Primero de Marzo el general golpista Andrés Rodríguez, derrocador de Stroessner, dijo todavía cosas como que el alzamiento había sido "por la unificación plena y total del coloradismo en el gobierno", sin darse cuenta del divorcio creciente entre la calle, las Fuerzas Armadas, el Partido Colorado y el gobierno. No en vano, el golpe de Estado de 1989 fue cosa de mandos militares y dirigentes del tradicionalismo dentro del Partido Colorado, sin que la oposición democrática tuviera cabida ${ }^{69}$.

Civilmente, las protestas universitarias se habían ido canalizando a través de la Federación de Estudiantes Universitarios del Paraguay (1987) y la Coordinadora de Estudiantes del Interior (1988), la cual el 14 de julio de 1990 dio paso a CEUNIRA (Centro de Estudiantes Universitarios del Interior Residentes en Asunción). La primera piedra de toque del nuevo gobierno fue la celebración de las elecciones legislativas y presidenciales de mayo de 1989, y sobre todo de las municipales y generales para Asamblea Constituyente de 1991, mientras Bush padre anunciaba el 27 de junio de 1990 la Iniciativa para las Américas, tendente a la creación de una zona americana de libre cambio.

\section{Paraguay en los años 90.}

En 1992 entró en vigor en Paraguay una nueva Constitución que prohibía la reelección del presidente, y ese mismo año salieron a la luz los Archivos del Terror, que daban cuenta de las atrocidades realizadas por el régimen de Stroessner. También se firmó un acuerdo de cooperación con la Comunidad Económica Europea (CEE), a pesar de lo cual la situación de Paraguay se veía como la de una democracia más cosmética que real, al estilo de lo que más o menos por aquellas fechas sucedía en Perú, Guatemala,

\footnotetext{
69 Véase Luis Galeano, “¿De la apertura otorgada a la transición pactada?”, Revista Paraguaya de
} Sociología no. 131 (2008): 54; publicado originalmente en 1989. 
Colombia, Haití, Brasil, etc ${ }^{70}$. En las elecciones presidenciales de 1993 ganó Wasmosy, del Partido Colorado. Las organizaciones juveniles se revelaron por entonces como nuevos actores en el escenario político-social paraguayo, rebasando el ámbito estudiantil y el de la Iglesia. Por ejemplo, en 1994 apareció en el Paraguay el Movimiento de Objeción de Conciencia (MOC).

Entre el 15 de agosto de 1993 y el 14 de agosto de 1998 gobernó el país el empresario Juan Carlos Wasmosy, un país en el que hasta 1997 no se creó el Conservatorio Nacional de Música $^{71}$, pero en el que en 1995 el PIB había crecido un 3,5 debido a las buenas cosechas y en el que la inflación fue del 13,9 \%, la más baja desde $1982^{72}$. A ello contribuyó sin duda la entrada en vigor el 1 de enero de 1994 del Tratado de Libre Comercio con Estados Unidos de América y Canadá. Sin embargo, en 1995 la crisis bancaria saltó a la palestra.

Los mayores impedimentos en la primera fase de la transición democrática paraguaya surgieron, no obstante, en abril de 1996 (intento de golpe de Estado), marzo de 1999 (crisis) y mayo de 2000 (de nuevo intento de golpe). A mediados de abril de 1996 el jefe del ejército, general Lino Oviedo, terminó de exacerbar a la opinión pública por sus incursiones políticas y partidarias de cara a las elecciones presidenciales de 1998, y el 22 de abril fue acusado de violar la ley que prohíbe a los militares realizar actividades políticas, lo que desembocó en su deposición. Sin embargo, Oviedo se resistió y el presidente Wasmosy, temiendo perder el control, llegó a un acuerdo con el militar y le nombró ministro de Defensa a cambio de su instancia de retiro voluntario. Sin embargo, a la hora de hacer efectivo este nombramiento Wasmosy se echó atrás. Esta estrafalaria inseguridad política tenía como telón de fondo una economía vacilante (quiebra de cuatro bancos y cinco instituciones de ahorro y crédito, restricciones comerciales brasileñas), la desconfianza de los países de la zona por el papel de plataforma del contrabando y las reivindicaciones sociales (huelgas generales convocadas por las cuatro centrales sindicales, la del 2 de mayo de 1996 duramente reprimida). El 29 de abril de 1996 se eligió presidente del Partido Colorado al neoestroessnerista Luis María Argaña ${ }^{73}$.

\footnotetext{
${ }^{70}$ Consejo de redacción, "1992: escuchar a América Latina”, Revista de Fomento Social no. 185 (1992), 22.

${ }^{71}$ Diego Sánchez Haase, La Música en el Paraguay (Asunción: El Lector, 1998), 42.

72 Serge Cordellier y Béatrice Didiot (dirs.), El estado del mundo. Anuario económico y geopolítico mundial. 2001 (Madrid: Akal, 2000), 509.

${ }^{73}$ Cf. Serge Cordellier y Béatrice Didiot (dirs.), El estado del mundo..., 508-9.
} 
Sorteado el intento de golpe de Estado de Lino Oviedo, el empresario Raúl Cubas Grau fue presidente de Paraguay entre el 15 de agosto de 1998 y el 28 de marzo de 1999. El 23 de marzo de 1999 llegó la crisis política cuando tres hombres con uniforme de combate asesinaron al vicepresidente, Luis María Argaña. Cinco días después el presidente Raúl Cubas, sospechoso de estar detrás del asesinato ${ }^{74}$, dimitió y su puesto lo ocupó Luis González Macchi, que integró en su gobierno a ministros del Partido Liberal Radical Auténtico (PLRA) y de Encuentro Nacional, formación de centro izquierda. En 2000 la primera de las formaciones mencionadas abandonó la coalición gubernamental.

La sociedad civil siguió entretanto abriendo cauces de participación: en octubre de ese año apareció el MOBE (Movimiento por el Boleto Estudiantil). La economía, mientras, se deterioró: el paro alcanzó en 1999 el 16 \% y la deuda externa ascendió a 2100 millones de dólares (el $22 \%$ del PIB).

El 19 de mayo de 2000 hubo un intento de golpe de Estado (atribuido a oficiales oviedistas) que provocó el estado de excepción y el encarcelamiento de más de 100 personas (militares, dirigentes políticos y periodistas ligados a Oviedo). Se eligió el 13 de agosto como fecha para la elección del nuevo vicepresidente, cargo que consiguió Julio César Franco (presidente del PRLA), rompiendo la hegemonía de 53 años del Partido Colorado $^{75}$.

\section{Paraguay en un nuevo milenio.}

Sin embargo, los problemas económicos siguieron ahí: por ejemplo, si en 1982 el producto per cápita era de unos 1400 dólares, en 2003 descendió hasta los 1000 dólares $^{76}$. En las elecciones de 2003 Nicanor Duarte, que había sido ministro de Educación con Wasmosy y González Macchi, salió victorioso y gobernó el país hasta el 15 de agosto de 2008.

El Partido Colorado, mantenedor de la ficción política del régimen golpista de Stroessner, siguió en el poder una vez desaparecido el dictador hasta que las elecciones

\footnotetext{
${ }^{74}$ La organización del asesinato de Argaña se sospechó que pudiera haber recaído en el general Lino Oviedo, quien se fue a Argentina después del atentado, pero regresó clandestinamente en diciembre de 1999.

75 Luis Costa Bonino, "Paraguay", en L'Etat du Monde S, (Coord.) Serge Cordellier y Béatrice Didiot. $2000,427$.

${ }^{76}$ Alejandro Vial, "El Paraguay en el mundo global: retos, desafíos y oportunidades", Revista Paraguaya de Sociología no. 129-130 (2007): 169.
} 
de 2008 permitieron el acceso a la presidencia del ex obispo de San Pedro, Fernando Lugo, merced a una coalición entre liberales y agrupaciones de izquierda, estas inmersas en el Frente Guasú ${ }^{77}$. Habían sido 61 largos años en el poder por parte del Partido Colorado. Por aquellas fechas, por citar un dato de su legado, se calculaba que el $50 \%$ de la economía paraguaya funcionaba "en negro" $" 78$.

El acceso de Lugo a la presidencia del país ${ }^{79}$ supuso una sorpresa y un relativo viraje a la izquierda ${ }^{80}$ que pronto Estados Unidos de América consideró peligroso ya que, en medio del crash financiero mundial, la posibilidad de que otro líder carismático de izquierda se hiciera con las riendas de un país sudamericano y diera al traste con las políticas neoconservadoras de no-injerencia estatal (denominadas en inglés de hand off) era algo que no veían beneficioso. EUA ya tenía demasiados quebraderos de cabeza en la zona, sobre todo con Chávez en Venezuela, Evo Morales en Bolivia y Rafael Correa en Ecuador.

Paraguay, afortunadamente, estaba cambiando lentamente su fisonomía. En 2009 el Departamento Central -donde se ubica Asunción- tenía la densidad poblacional más alta del país (637.249 habitantes), y su área metropolitana -Gran Asunción- alcanzaba los 1.982.773 habitantes de un total de 6.996.245 personas viviendo en el país ${ }^{81}$. Casi el 95 \% lo hacía en la Región Oriental. También la denominada sociedad civil estaba cambiando su manera de organizarse.

Los impedimentos en el desarrollo de la acción de gobierno de Fernando Lugo fueron muy variados e incluyeron un asunto de paternidad en abril de 2009 y el secuestro de Fidel Zabala el 15 de octubre del mencionado año por parte del fantasmal y enigmático Ejército del Pueblo Paraguayo, secuestro resuelto felizmente el 17 de enero de 2010. Sin embargo, hacia mediados de agosto de 2009 era patente el desencanto entre muchas de

\footnotetext{
${ }^{77}$ Incluyendo al Partido Revolucionario Febrerista, el Partido Comunista y el Partido Demócrata Cristiano.

${ }^{78}$ Pablo Herken Krauer, "Situación de la economía paraguaya”, Revista Paraguaya de Sociología no. 131 (2008): 148.

${ }^{79}$ En el Senado ganó el Partido Colorado por menos del $1 \%$.

${ }^{80}$ Durante el año y medio que pasó Lugo recorriendo el país y difundiendo su mensaje propuso la estrategia del desarrollo "mbytetepe, poncho juruicha" ("exacto en el medio, como la boca del poncho"), haciendo referencia a una política centrista. Arístides Ortiz, "Paraguay: Lugo se aleja de los movimientos sociales y de las izquierdas", 2009. Consultado el 15 de marzo de 2013. http://www.nodo50.org/ceprid/spip.php?article565\&lang=es

81 A pesar de lo cual sociológicamente Asunción es la ciudad más rural de Hispanoamérica. Domingo Rivarola, "Estado, sociedad civil y proceso educativo", Revista Paraguaya de Sociología no. 131 (2008): 165-166.
} 
las personas que le habían apoyado ${ }^{82}$. En noviembre hubo elecciones municipales. El país remontaba económicamente en 2010 (tasa de crecimiento del 14,5\%, la mayor de Hispanoamérica), pero el reparto seguía siendo desigual, con una extrema pobreza de alrededor del $19 \%$.

A mediados de 2011, cumplidos tres años de gobierno de Fernando Lugo, se estaba en general de acuerdo en que se habían producido durante su mandato avances en salud, macroeconomía (crecimiento del $15 \%$ en 2010) e Itaipú (aumento de 120 a 360 millones de dólares en el pago por la energía que se cede a Brasil), mientras que se criticaba su actuación (o falta de ella) en asuntos como la seguridad y los problemas campesino e indígena ${ }^{84}$. A ello había que añadir la impotencia para cambiar la situación fiscal en el país: recuérdese que Fernando Lugo sólo contó con tres senadores y una diputada en el Congreso Nacional. En Paraguay en 2011 había un 84 \% de afiliados a partidos (más de 2 millones y medio de personas), aunque curiosamente había 550.000 electores que estaban afiliados a dos, tres o más partidos de manera simultánea ${ }^{85}$.

Algunos pensaban que la normalidad democrática sería un hecho a partir del acceso al poder de Fernando Lugo a través de su Alianza Patriótica para el Cambio (APC). En este sentido, se pedía por parte de algunos sectores sociales el día 2 de febrero de 2012 el resarcimiento a las víctimas de Stroessner coincidiendo con el $23^{\text {er }}$ aniversario de la caída del dictador. La Comisión de la Verdad y la Justicia había señalado en agosto de 2008 que había conseguido documentar 425 ejecutados o desaparecidos, casi 20.000 detenidos (no pocos de ellos torturados) y 20.814 exiliados durante el período de terror estronista $^{86}$. Frente a ello, sólo se habían abierto unas 80 causas penales. No es de extrañar que el desencanto siguiera formando parte del ambiente político. Así Martín Almada, una de las personas que contribuyeron a que en 1992 los Archivos del Terror de la dictadura estronista salieran a la luz, dijo en febrero de 2012: “Aquí poco o nada ha cambiado.

\footnotetext{
82 Véase, por ejemplo, Arístides Ortiz, "Paraguay: Lugo se aleja de los movimientos sociales y de las izquierdas".

${ }^{83}$ Quintín Riquelme, "Lo social en el gobierno Lugo: de la esperanza a la incertidumbre”, Acción no. 317 (2011): 23.

${ }^{84}$ Véase “Un pequeño cambio, ¿es mucho o nada?", Acción no. 317 (2011): 4. En datos de 2011, la pobreza en el área rural alcanzaba a 1.182.112 personas, llegando a la extrema pobreza 782.009. Dionisio Borda, "Nuevas señales y viejos problemas", Economía y Sociedad (2013): 10.

${ }^{85}$ Domindo Rivarola, "De la soberanía y representación”. Acción no. 317 (2011).

86 http://noticias.lajornada.ca/146_sociedad/1453501_las-victimas-de-stroessner-siguen-pidiendoreparacion-y-justicia-23-anos-despues.html, consultado el 4 de enero de 2013. Sobre las dificultades, cf. http://internacional.elpais.com/internacional/2012/02/21/actualidad/1329855402_524683.html, consultado el 5 de enero de 2013.
} 
Cambió el régimen político, pero siguió la naturaleza corrupta del Estado", y remató: "Se fue Stroessner y Rodríguez dejó a todos los estronistas en el poder, por eso es que hay impunidad en este país" ${ }^{" 87}$. La situación de Paraguay era muy delicada por entonces debido a que las rémoras enumeradas se unían a un panorama de déficit externo, inestabilidad cambiaria, inflación, elevada deuda externa y desempleo, con un mercado laboral desestructurado e informal y tremendamente desequilibrado en la distribución de la riqueza y de la renta. Sin embargo, Paraguay quería dar un paso adelante y mostrarse al mundo con normalidad. En este sentido, en 2011 fue sede de la XXI Cumbre Iberoamericana.

\section{Curuguaty y la caída de Fernando Lugo.}

A veces uno está tentado a pensar que los países, conociendo o no su historia, están abocados a repetirla. En el caso de Paraguay, el 15 de junio de 2012 en el sudeste del país, concretamente en Curuguaty (departamento de Canindeyú), los intereses de algunos poderes internacionales y oligárquicos del país volvieron con nefandos métodos a ser los protagonistas de la vida política del Paraguay.

La ocupación de tierras por parte de campesinos en Paraguay se remontaba al menos a las primeras décadas del siglo $\mathrm{XX}^{88}$. En los años 80, entre 1983 y 1986, por ejemplo, al menos 15.000 familias habían ocupado fracciones de tierras no explotadas ${ }^{89}$ y a la altura de 1989 se estimaba en 110.000 los campesinos sin tierra ${ }^{90}$.

El caso es que desde abril de 2012 se habían visto por la zona de Curuguaty matones al servicio de los dueños de una finca de 2000 hectáreas conocida con el nombre de Marina Cué. En Nacunday, donde habían estado asentadas ocho mil personas sin tierra (carperos), había sucedido algo parecido durante una desocupación. El caso es que en Curuguaty, durante otro proceso de desocupación, diecisiete vidas fueron segadas de raíz (6 policías y 11 campesinos) y hubo también 20 heridos en el intento de echar de allí a 70

\footnotetext{
87 http://noticias.lajornada.ca/146_sociedad/1453501_las-victimas-de-stroessner-siguen-pidiendoreparacion-y-justicia-23-anos-despues.html, consultado el 5 de enero de 2013.

88 Cf. Ramon Forgel, "Las invasiones de tierras: una respuesta campesina a la crisis"; y "Tierra y democracia. La lucha de los campesinos paraguayos".

89 Ramon Forgel, "Tierra y democracia. La lucha de los campesinos paraguayos", 280.

${ }^{90}$ Dionisio Borda, "Cambio y continuismo: persisten los grandes desafíos económicos para el Paraguay del 90", 307.
} 
personas en una acción vigilada por 324 policías $^{91}$. Ya en el mandato de Lugo se habían producido desalojos, en algunos casos muy violentos, de tierras rurales y urbanas, pero el caso de Curuguaty, muy probablemente orquestado de una manera siniestra ${ }^{92}$, sirvió de excusa para que el inestable Parlamento procediera a quitar de en medio a Fernando Lugo. En un tiempo récord (menos de un día se dio al Presidente para ejercer su derecho a la defensa) el Parlamento destituyó a Fernando Lugo a través de un impeachment escenificado en dos horas. El 22 de junio de 2012 el vicepresidente, Federico Franco (Partido Liberal), asumió la Presidencia de Paraguay.

Anteriormente se había amenazado con la destitución del presidente a través de juicio político, pero no se habían encontrado argumentos sólidos ${ }^{93}$. Según Richer, ministro de Acción Social con Fernando Lugo, este fue amenazado de juicio político en más de 20 ocasiones $^{94}$.

El cambio de mandatario fue acogido con protestas en diversas localidades e incluso en la Plaza de Armas de Asunción se mezclaron dirigentes estudiantiles, campesinos y diversas organizaciones sociales. La oposición interior quiso hacerse fuerte formando el Frente por la Defensa de la Democracia ${ }^{95}$ y la Conferencia Episcopal Paraguaya dirigió una carta a sacerdotes, religiosos y laicos el 28 de agosto en la que se ponían en evidencia los diferentes criterios existentes en su seno. En el ámbito internacional, hacia fines de junio de 2012 tan sólo España (Mariano Rajoy), el Vaticano (Benedicto XVI), Alemania (Angela Merkel) y Canadá (Stephen Harper) habían reconocido al nuevo presidente paraguayo, mientras que se mostraron especialmente beligerantes en su contra los gobiernos de México (Felipe de Jesús Calderón), Colombia (Juan Manuel Santos), Bolivia (Evo Morales), Ecuador (Rafael Correa), Perú (Ollanta Humala), Venezuela (Hugo Chávez), Brasil (Dilma Vana Rousseff), Uruguay (José Mujica), Argentina (Cristina Fernández), Chile (Sebastián Piñera), El Salvador (Mauricio

\footnotetext{
${ }^{91}$ Existe un documental titulado Detrás de Curuguaty (2012) que recoge testimonios, entre otras personas, de varios campesinos imputados, y con posterioridad se ha presentado un libro sobre el asunto. Julio Benegas, La masacre de Curuguaty (Asunción: Arandurá, 2013).

92 Quintín Riquelme, "Lo social en el gobierno Lugo: de la esperanza a la incertidumbre”, Acción no. 317 (2011): 21.

${ }^{93}$ Quintín Riquelme, "Lo social en el gobierno Lugo: de la esperanza a la incertidumbre”, 20.

${ }^{94}$ Hugo Richer, "Seis preguntas y seis respuestas sobre la crisis paraguaya". 2012, consultado el 15 de marzo de 2013. http://www.nodo50.org/ceprid/spip.php?article1561\&lang=es.

${ }^{95}$ Durante el mandato de Lugo existieron tres frentes en el país: el Frente por un País para la Mayoría, el Frente Social y Popular, y el Frente Patriótico y Popular. Quintín Riquelme, "Lo social en el gobierno Lugo: de la esperanza a la incertidumbre", 22.
} 
Funes), Nicaragua (Daniel Ortega), Cuba (Raúl Castro) y la República Dominicana $\left(\right.$ Leonel Fernández) ${ }^{96}$.

No por casualidad quien usaba el terreno en litigio de Curuguaty no era otro que el empresario Blas N. Riquelme, que había apoyado el golpe de Andrés Rodríguez en 1989 y que desde 2004 pedía ante la justicia la posesión de la finca y la expulsión de los sin tierra. Riquelme, ya fallecido, fue uno de los dos que condujeron por parte de la Fiscalía las pesquisas de los hechos sucedidos allí. Ante las más que previsibles deficiencias en la investigación oficial el liberal Domingo Laíno fundó la Plataforma de Estudio e Investigación de Conflictos Campesinos (PEICC) poco después de la destitución de Lugo con el objetivo de radiografiar la investigación. A pesar de ello, en octubre de 2012 se dio por finalizado el informe de la investigación sin que ni siquiera se supieran oficialmente los resultados de las autopsias y de balística. Según la Fiscalía, los agentes policiales cayeron en una emboscada "previamente preparada y planeada" por sin tierra armados con rifles, escopetas, hoces y machetes.

En medio de la situación de crisis, y para que la XXII Cumbre Iberoamericana (Cádiz, 16-17 de noviembre de 2012) saliera adelante, se presionó internacionalmente al nuevo presidente paraguayo, Federico Franco, para que no acudiera y de esta forma no hubiera boicot por parte de los países de MERCOSUR y UNASUR.

El 20 de noviembre de 2012 cientos de personas marcharon desde el Panteón de los Héroes hasta la Fiscalía pidiendo la libertad de los 10 campesinos sin tierra que se encontraban aún detenidos y acusados por los sucesos de Curuguaty, llevando ocho de ellos 2 meses de ayuno ${ }^{97}$. Rubén Villalba tuvo la suerte de ser el único dirigente de la ocupación que quedó con vida y, señalado como el responsable principal de la tragedia, fue recluido en la hacinada cárcel asuncena de Tacumbú acusado de la muerte de seis policías. Curuguaty parece ser un lugar especialmente lúgubre en la historia paraguaya, ya que allí el mariscal Francisco Solano López en 1869, durante su patética retirada, fusiló y torturó a varias personas de su propio entorno.

Desde una lectura política más global el cambio de gobierno en Paraguay fue interpretado por algunos analistas como una continuación de lo sucedido en Honduras en

\footnotetext{
${ }^{96} \mathrm{http}: / /$ www.bolpress.com/art.php?Cod=2012062601, consultado el 18 de enero de 2013.

97 http://www.telesurtv.net/articulos/2012/11/20/paraguayos-manifiestan-por-la-libertad-de-campesinospresos-por-caso-curuguaty-3376.html, consultado el 6 de enero de 2013.
} 
2009 contra Manuel Zelaya en el sentido de debilitar los gobiernos progresistas emergentes de Hispanoamérica.

\section{Paraguay en 2013.}

Se calculó por parte del FMI que la economía de Paraguay crecería en 2013 un 11 \%. El año 2012 Paraguay lo cerró con una inflación del 4 \%, año en el que Paraguay consumió apenas un $10 \%$ de la energía producida por la hidroeléctrica Itaipú, una de las dos hidroeléctricas binacionales de las que Paraguay es socio (la otra es la de Yacyretá), y para 2013 esperaba casi doblar el consumo. El propósito del gobierno paraguayo era promover la industrialización del país más allá de la constante ampliación del sector financiero ${ }^{98}$; en este sentido parece, por ejemplo, que la procesadora de aluminio Rio Tinto Alcan (Montreal, Canadá) instalará una planta en Paraguay ${ }^{99}$ al calor de la ley 60/90 de estímulo a la inversión ${ }^{100}$. Junto con ello, se pretende promover una clase media en el país, aunque queda por ver si la lección del pasado se ha aprendido y dicha clase no es ahogada por los impuestos y obligada a huir debido a los bajos sueldos y a la inestabilidad política. La presión tributaria se sitúa en Paraguay en torno al $11 \%$, siendo el IVA el que recauda el $45 \%$. Al basarse los impuestos en el consumo y no en las ganancias, las corporaciones transnacionales pagan pocos impuestos (aranceles aduaneros por importaciones, impuesto a la renta de las empresas e impuesto a la renta agropecuaria), estando exenta la exportación de materias primas ${ }^{101}$.

Persisten grandes focos de pobreza y está aumentando el deterioro medioambiental. Sanitariamente, epidemias del dengue como la sufrida desde enero de 2013 son claros indicadores de la precariedad de las condiciones médicas ${ }^{102}$. Además,

\footnotetext{
98 Todavía pesa como una losa el lema que utilizó la Unión Industrial Paraguaya en la dictadura de Stroessner: "Consuma lo que el Paraguay produce", producto de una burguesía que tradicionalmente ha atendido sus latifundios, rentas y especulaciones sin ocuparse apenas del sector industrial.

99 http://www.americaeconomia.com/negocios-industrias/paraguay-consumira-8-mas-de-energia-deitaipu-en-2013, consultado el 5 de enero de 2013.

100 No obstante, su apertura ha causado profunda división en la opinión pública paraguaya ya que la transnacional ha sido acusada repetidamente por contaminación ambiental y violaciones de los derechos humanos. Fernando Masi, "Rio Tinto Alcan: la complejidad de una inversión", Economía y sociedad no. 4 (2012).

${ }^{101}$ Luis Rojas Villagra, Paraguay. Corporaciones transnacionales y agronegocios. Las Corporaciones Transnacionales en Paraguay, 2010, consultado el 14 de marzo de 2013. http://elpolvorin.overblog.es/article-paraguay-corporaciones-transnacionales-y-agronegocios-luis-rojas-villagra54708301.html.

${ }^{102}$ Más de 10.000 casos de dengue se detectaron apenas alcanzado el mes de febrero. Verónica Serafini Geoghegan, “Epidemias de dengue: ¿reflejan la situación del sector público y la ciudadanía paraguaya?”. Economía y sociedad no. 5 (2013): 7.
} 
como una amenazante sombra de la que parece imposible despegarse, a principios de 2013 todavía se sigue temiendo a la policía, a los militares y a los pyragues (informantes de la policía). Se diría que el índice de Desarrollo Humano del Paraguay deja todavía mucho que desear y que a día de hoy, en palabras de Tomás Palau, "el modelo agroexportador del agronegocio" juega un rol fundamental en el empobrecimiento del país debido a "la ocupación de grandes extensiones de tierra, la mecanización expulsora de mano de obra, la emigración del campo a la ciudad, la deforestación, la contaminación del suelo y el agua y varios otros mecanismos"103. La formación en abril de 2005 de la Unión de Gremios de la Producción (UGP) no ha hecho sino reforzar los intereses de las empresas más boyantes de la agroexportación.

\section{El control de la producción paraguaya.}

En 2007 operaban directamente en la economía paraguaya 12 transnacionales en el llamado agronegocio: cinco estadounidenses, seis europeas y una asiática ${ }^{104}$. Los productos de Monsanto se distribuyen a través de las empresas locales Dekalpar y Agrofértil (ésta con propietarios de origen brasileño). ADM Paraguay es la mayor importadora de semillas y agroquímicos, por delante de Cargill. Por su parte, Monsanto comercializa sus semillas transgénicas y agroquímicos a través de varias empresas, siendo la más importante Agrofértil, viniendo después Dekalpar, que también comercializa productos de la transnacional Bayer. La suiza Syngenta distribuye sus productos a través de Agrosan. Los insumos agrícolas se importan sobre todo a través de Agrotec (inversión brasileña), que produce sus propios agroquímicos y también importa y comercializa los de transnacionales como Basf, Pioneer y Bunge. Se trata de la cuarta empresa importadora de Paraguay, por detrás de Petropar y dos empresas reexportadoras del sector informático. De esta manera, las transnacionales juegan el papel de proveedoras de la producción agrícola y acopiadoras de esa misma producción.

En cuanto a las exportaciones, son seis las transnacionales que operan, cinco de ellas también dedicadas a las importaciones. Todas ellas manejan el $40 \%$ de las exportaciones del país. El producto estrella es la soja en grano, complementada con el aceite y la harina. La principal transnacional exportadora es Cargill, que se instaló en

${ }^{103}$ Tomas Palau, "Los actores del modelo: gremios y empresarios bien alineados", Acción no. 317 (2011): 15 .

${ }^{104}$ En lo que sigue me baso en Luis Rojas Villagra, Paraguay. Corporaciones transnacionales y agronegocios... 
Paraguay en 1978 y se dedica sobre todo a la soja en grano. ADM Paraguay Saeca es la segunda en importancia y lleva en el país desde 1997. Construye sus convoyes de barcazas por medio del grupo Naviera Chacho. En tercer lugar se ubica Bunge Paraguay, que ha crecido mucho últimamente. Noble Paraguay (anteriormente Baelpa) tiene su casa matriz en Hong Kong y también ha crecido mucho comerciando con la soja en grano. Louis Dreyfus Paraguay, de origen francés, se dedica al algodón y los granos. Contiparaguay (antes Capsa) pertenece desde 1996 a la transnacional angloholandesa Uniliver y se dedica al procesamiento y elaboración de aceites, harinas y otros productos, y también a la exportación de semillas oleaginosas.

Si hablamos de la industrialización de materias primas, hay cinco empresas que representan en Paraguay a cuatro transnacionales. Tres realizan procesos de industrialización en el propio Paraguay: Cargill, Contiparaguay y Parmalat, y dos -Nestlé y Uniliver- realizan la industrialización en sus filiales de otros países, limitándose en Paraguay a importar y distribuir sus productos. La planta industrial de Cargill se halla en Minga Guazú (Alto Paraná). Parmalat Paraguay, filial de la transnacional italiana, posee la suya en San Lorenzo, comercializando toda su producción en el mercado interno. Por su parte, Nestlé Paraguay es una filial de la empresa agroalimentaria más poderosa del mundo cuya sede central está en Suiza, e importa productos alimenticios elaborados principalmente en Brasil, poseyendo una larga lista de marcas y productos (Leche Nido, Nescafé, Nesquik, La Lechera, Purina, etc.) que se comercializan sobre todo a través de supermercados. Uniliver de Paraguay importa productos elaborados por la transnacional en otros países, sobre todo alimentos, productos de limpieza y de higiene personal (Close Up, Knorr, Lipton, Rexona, Dove, Arisco, Maizena, etc.). Contiparaguay industrializa más que nada aceites y harinas, y envasa jabones y detergentes para Uniliver. Su establecimiento industrial se ubica en Capiatá. De esta manera, el sector industrial exporta sólo aceite y harina, mientras que importa muchos productos de alto valor agregado.

A todos los anteriores productos hay que sumar el agua dulce proveniente del Acuífero Guaraní, que en Paraguay tiene una explotación sobre todo para el consumo a través de unos 200 pozos, recurso que los Estados Unidos de América quieren controlar 
y para ello llegaron a un acuerdo con el gobierno paraguayo para la apertura de una oficina del FBI. ${ }^{105}$

Luis Rojas piensa que:

\begin{abstract}
"El modelo del agronegocio, hegemonizado ampliamente por el núcleo transnacional en Paraguay, es un modelo que produce enormes ingresos para estas empresas, generando escasos empleos, y dejando pocos ingresos laborales e impuestos en el país, aumentando la concentración de las actividades económicas y sus beneficios, y por tanto, aumentando la desigualdad económica y social, tanto dentro como fuera del país"106.
\end{abstract}

La industria cultural ${ }^{107}$, que se centra en la capital, está poco desarrollada y las políticas para dinamizarla son recientes, existiendo áreas copadas por las industrias extranjeras, como el cine y la música popular moderna. La Ley Nacional de Cultura (2006) ha tenido poca incidencia y en 2008 se creó la Secretaría Nacional de Cultura (SNC), que tiene varias direcciones, una de ellas llamada de Fomento del Libro. Se han creado el Premio Nacional de Literatura y el Premio Municipal de Literatura. La iniciativa privada tiene su máxima manifestación en el Centro de Artes Visuales/Museo del Barro, reconocido en el ámbito internacional de Hispanoamérica. Sin embargo, sigue siendo la cultura popular la que tiene más aceptación: teatro popular, carnavales de Encarnación, festivales de Chamamé, etc., y aunque hay actividades culturales internacionales, éstas no tienen repercusión ni dentro ni fuera del país (Festival Internacional de Cine, Semana Internacional de Teatro, Feria del Libro, el Ojo Salvaje, Festival Mundial del Arpa, etc.). Los grandes artistas paraguayos (especialmente sobresalientes en música, teatro y danza) son escasamente potenciados nacional e internacionalmente. La producción cinematográfica anual hasta hace poco alcanzaba como máximo a tres películas que además no llegaban a las salas comerciales. Esto parece estar cambiando y el máximo exponente es la película paraguaya 7 Cajas, rodada en 2010, que en 2013 fue seleccionada para los Premios Goya españoles en el apartado de "mejor película extranjera de habla hispana” después de haber competido en el Festival de Cine de San Sebastián (España), donde ganó el galardón llamado "Cine en construcción”. Ha supuesto todo un revulsivo ya que se estrenó el 10 de agosto de 2012 y en poco más de un mes la habían visto 160.000

\footnotetext{
105 Véase Lester Martínez Argudín, "Importancia geoestratégica del Acuífero Guaraní para América", (2010), consultado el 15 de marzo de 2013. http://www.nodo50.org/ceprid/spip.php?article903\&lang=es. ${ }^{106}$ Luis Rojas Villagra, Paraguay. Corporaciones transnacionales y agronegocios...

107 Aquí sigo fundamentalmente los datos del Plan 2011. Centros Culturales de España. Centro Cultural Paraguay Asunción (Madrid: Ministerio de Asuntos Exteriores y de Cooperación, AECID, 2011).
} 
personas, todo un récord para el cine paraguayo. En 2012, por otro lado, entró en vigor una nueva Ley de Lenguas ${ }^{108}$.

Desde el punto de vista educativo, está claro que la existencia de muchas universidades no da necesariamente como fruto una buena instrucción: Paraguay cuenta con 54 organismos de este tipo que en no pocos casos parecen más dispensadoras de títulos que instituciones formadoras del alumnado.

Mientras Paraguay se preparaba para sus elecciones en 2013, algunas de las corporaciones estadounidenses con grandes posesiones de tierra en el país -con antecedentes tan remotos como la planta envasadora de carne establecida en $1917^{109}$ eran: American Coffee Corporation (Jersey City, NJ), Standard Oil of New Jersey (Exxon) -usufructuaria de 6 millones de hectáreas-, Anderson Clayton Corporation (Fresno, CA), dedicada al algodón, y Gulf and Western Industries, Inc. (Nueva York). Por otro lado, Paraguay es el cuarto país exportador de soja del mundo, después de Estados Unidos de América, Brasil y Argentina, y el sexto país productor (2,8 millones de hectáreas sembradas en 2010-1), siendo su primer producto de exportación. Su cultivo en Paraguay se expandió a partir de 1973. Para la explotación del negocio funcionan en Paraguay filiales de las siguientes multinacionales: Archer Daniels Midland (Decatur, Illinois), Cargill Inc. (Mineápolis, MN), Bunge Ltd. (White Plains, NY), Louis Dreyfus (Stamford, CT) -las tres últimas dedicadas a la exportación-, ADM -que en 2010 abrió en Villeta la primera planta paraguaya de mezcla de fertilizante a gran escala- y Noble (Stamford, CT). Los grandes cultivos paraguayos se enfrentan a una encrucijada debido a los transgénicos y a los agroquímicos ${ }^{110}$. En Argentina, en 2009, después de trece años de agronegocio a base de soja transgénica, comenzaron a levantarse voces contra las consecuencias socioambientales y la formación de una "República Unida de la Soja" en el Cono Sur ${ }^{111}$.

\footnotetext{
${ }^{108}$ Véanse las líneas muy críticas de Hannes Kalisch, "La Ley de Lenguas y los pueblos indígenas", Acción no. 321 (2012), desde la perspectiva del desarrollo de las lenguas indígenas distintas del guaraní.

${ }^{109}$ Que hay que situar en el contexto del desarrollo de industrias locales producido por los efectos de la Primera Guerra Mundial sobre los países beligerantes.

${ }^{110}$ Véase Miguel Lovera, "Transgénicos en la agricultura: una imposición motivada ideológicamente", Acción no. 328 (2012): 8-11; y José Luis Insfrán, "Enfermedades hematológicas y transgénicos", Acción no. 328 (2012): 12-3.

${ }^{111}$ Cf. Grain, "Trece años de soja en Argentina: las consecuencias inevitables de un modelo genocida y ecocida", 2009. consultado el 15 de marzo de 2013. http://www.nodo50.org/ceprid/spip.php?article576\&lang=es
} 
En el terreno armamentístico, la empresa militar privada Alliant Techsystems (ATK) administra un complejo militar estadounidense de Salt Lake City (Utah) que exporta armas y municiones a Paraguay a través de la empresa Sake Saci. Por su parte, las históricas prospecciones petrolíferas en el Chaco paraguayo dieron resultados negativos a la Standard Oil de Nueva Jersey, a la Royal Dutch Sell, a la Union Oil de California (su contrato data de 1944) y a la Pure Oil Company, aunque no se sabe lo que pueda depararnos el futuro.

Otras riquezas paraguayas, como el negocio de la carne vacuna, afectado por un brote de fiebre aftosa a fines de $2011^{112}$, han tenido una historia complicada desde que en 1962 la COPACAR (Compañía Paraguaya de Carne) perdiera el monopolio por obra y gracia del Plan de 1962 del Banco Mundial ${ }^{113}$. En lo que se refiere al maíz, en 2013 estaba previsto su cultivo en 1.250.000 hectáreas, habiéndose permitido a fines de octubre de 2012 la plantación de cuatro tipos de maíz transgénico ${ }^{114}$, negocio controlado por multinacionales como Monsanto (St Louis, MO). A través del Plan Nacional del Trigo comenzó a inicios de los 80 el cultivo a gran escala de dicho cereal (Mora Mérida 1981, 92). Por otro lado, si en Paraguay había existido una cierta industria dedicada a la fabricación de bebidas, con la aparición de plantas embotelladoras de Pepsi-Cola y CocaCola desde fines de 1966 el sector evidentemente se ha resentido mucho ${ }^{115}$.

\section{El regreso de los colorados.}

Políticamente el mandato de Federico Franco expiraba en agosto de 2013, y cumplió su promesa de no presentarse a las siguientes elecciones, convocadas finalmente para el 21 de abril de 2013, en las que estuvieron inscritas unas 3.600.000 personas ${ }^{116}$. El candidato del Partido Liberal fue el senador Efraín Alegre, Ministro de Obras Públicas y Comunicaciones en tiempos de Fernando Lugo. Por el Partido Colorado el candidato fue Horacio Cartes, empresario formado sobre todo en EUA y de reciente afiliación al Partido

\footnotetext{
112 http://www.americaeconomia.com/economia-mercados/finanzas/paraguay-mantiene-su-tasa-depolitica-monetaria-en-55, consultado el 5 de enero de 2013.

${ }^{113}$ Hacia la mitad de los años 60 del siglo XX las filiales de las empresas estadounidenses habían alcanzado el número de más de 3000 fábricas que en ocasiones entraban en competencia con sus casas centrales incluso en los propios EUA. Maurice Crouzet (dir.), Historia general de las civilizaciones. La época contemporánea. Tomo 1. En busca de una nueva civilización (Barcelona: Destino, 1982), 582.

$114 \mathrm{http} / / / \mathrm{www}$.lanacion.com.py/articulo/96494-gobierno-libero-4-tipos-de-maiz-transgenico.html, consultado el 12 de febrero de 2013.

115 José Luis Mora Mérida, Paraguay y Uruguay contemporáneos, 112-3; Eduardo Galeano, Las venas abiertas de América Latina, 322.

${ }^{116}$ Paraguay tiene ahora mismo unos 6.500.000 habitantes.
} 
Colorado (año 2009). Para complicar las semanas previas a las elecciones, el 2 de febrero de 2013 Lino Oviedo, que iba a ser el candidato por parte de la tercera fuerza política del país, el PUNACE (Partido Unión Nacional de Ciudadanos Éticos) -una secesión del Partido Colorado-, murió en lo que oficialmente se ha descrito como un accidente aéreo. En opinión de J. C. Rodríguez, con Oviedo moría "el último caudillo militar contemporáneo que pretendía apoderarse del poder con el uso ilegal de la institución castrense, defensor del autoritarismo irrestricto" ${ }^{117}$.

El Partido Colorado venció en las elecciones del 21 de abril de 2013, algo que el sentido común dictaba que ocurriría después de que los paraguayos se encontraran desencantados después de la ilusión en gran parte no correspondida que habían depositado en Fernando Lugo en el año $2008^{118}$. Queda por ver si lo que se ha presentado como back to basics no es más que, de nuevo, una manera como otra cualquiera de, fundamentalmente, seguir dando la espalda a los verdaderos intereses de los paraguayos.

En este caminar por las sendas políticas y económicas $-\mathrm{y}$ en menor medida sociales y culturales- de Paraguay, podríamos haber escogido como compañeras algunas obras-clave de aquel Roa Bastos que mencionamos casi al principio, en el año 1947, cuando era un periodista. Su libro de cuentos El trueno entre las hojas apareció en 1953; Hijo de hombre es del año 1959 y tiene como marco de referencia un Paraguay rural; Yo, el supremo es de 1974 y en ella nos habla de Gaspar Rodríguez de Francia-Alfredo Stroessner; El fiscal que nos ha llegado a nosotros se publicó en 1994 y produce una serie de reflexiones sobre la relación amo-esclavo; y Los conjurados del Quilombo del Gran Chaco, de 2001, se va atrás en el tiempo hasta los hechos de la Guerra de la Triple Alianza, como intentando buscar una explicación a la aparente incapacidad del país para solucionar sus conflictos de manera pacífica y democrática.

\section{BIBLIOGRAFÍA}

ABENTE, Diego. "Límites y posibilidades: perspectivas de la democratización en el Paraguay”. Revista Paraguaya de Sociología no. 131 (2008): 11-35.

ACEVEDO, Euclides. “Aproximación a la realidad paraguaya: algunas ideas básicas para la transición". (Ed.) D. Koniecki (1986): 169-179.

\footnotetext{
117 José Carlos Rodríguez, “Querella en la sucesión de Lino O”. Economía y sociedad no. 5(2013): 6.

${ }^{118}$ Ilusión que se reflejó internacionalmente en el libro de Hugh O’Shaughnessy, The Priest of Paraguay: Fernando Lugo and the Making of a Nation (Londres: Zed Books, 2009).
} 
BENEGAS, Julio. La masacre de Curuguaty. Asunción: Arandurá, 2013.

BEDOYA, Esteban. "La literatura paraguaya, de la dictadura hasta hoy". En Crónicas y ensayos paraguayos de ayer y hoy, tomo I, coordinado por Teresa MÉNDEZ-FAITH. Asunción: Intercontinental, 2009.

BORDA, Dionisio. "Cambio y continuismo: persisten los grandes desafíos económicos para el Paraguay del 90”. Síntesis no. 10 (1990): 301-309.

BORDA, Dionisio. "Nuevas señales y viejos problemas”. Economía y Sociedad (2013): 9-11.

BUCHBINDER, Pablo. "Gente decente y "paysanos" contra la guerra: dimensiones de la resistencia a la Triple Alianza en la provincia de Corrientes”. Iberoamericana. América Latina-España-Portugal 12, no. 47 (2012): 29-48.

CANESE, Ricardo. "Paraguay. Franco, el nuevo Stroessner”. Sin Permiso (2012).

CAZAL, Atilio. "Paraguay: un país hipotecado". Nueva Sociedad no. 73 (1984): 15-18.

CORDELLIER, Serge y Béatrice DIDIOT (Dirs.). El estado del mundo. Edición 1997. Anuario económico y geopolítico mundial. Madrid: Akal, 1996.

El estado del mundo. Anuario económico y geopolítico mundial. 2001.

Madrid: Akal, 2000.

COSTA BONINO, Luis. "Paraguay". En L Etat du Monde S, coordinado por Serge Cordellier y Béatrice. 2000.

CROUZET, Maurice (Dir.). Historia general de las civilizaciones. La época contemporánea. Tomo 1. En busca de una nueva civilización. Barcelona: Destino, 1982. CUEVAS, Alberto. Sindicato y poder en América latina. Modelos y tendencias del sindicalismo latinoamericano. Madrid: Alianza América, 1990. (ed. original: Sindicato e potere nell'America latina. Modelli e tendenze nel sindicalismo latinoamericano. Roma, 1985).

DÍAZ, Leonardo. Lula. Barcelona: Folio, 2005.

DINGES, John. Operación Cóndor. Una década de terrorismo internacional en el Cono Sur. Santiago de Chile: Ediciones B, 2004.

Consejo de Redacción, 1995. "1992: escuchar a América Latina”, en Sociedad y economía en los años 90. Reflexiones de la Revista de Fomento Social, Córdoba, 19-26. FERNÁNDEZ ESTIGARRIBIA, José Félix. "Perspectiva de cambio de la política exterior paraguaya". Revista Paraguaya de Sociología no. 131 (2008): 183-192. 
FORGEL, Ramón. "Las invasiones de tierras: una respuesta campesina a la crisis". En Los movimientos sociales en el Paraguay, compilado por Domingo Rivarola y otros. Asunción: CPES, 1986.

. "Tierra y democracia. La lucha de los campesinos paraguayos". Síntesis no. 10 (1990): 275-87.

GALEANO, Eduardo. Las venas abiertas de América Latina. Madrid: Siglo XXI, 1980.

GALEANO, Luis. “¿De la apertura otorgada a la transición pactada?”. Revista Paraguaya de Sociología no. 131 (2008): 53-68.

GARCÍA ALVARADO, José María. Uruguay. Madrid: Alcalá, 1988. , y Javier GUTIÉRREZ PUEBLA. Paraguay. Madrid: Anaya, 1989.

GIURIA, Juan. La arquitectura en el Paraguay. Buenos Aires: Instituto de Arte Americano e Investigaciones Estéticas, 1950.

GONZÁlEZ DEL VALLE, Alcibíades. El Drama del 47: Documentos Secretos de la Guerra Civil. Asunción: El Lector, 1987.

GRACIARENA, Jorge y Rolando Franco. Formaciones sociales y estructuras de poder en América Latina. Madrid: Centro de Investigaciones Sociológicas, 1981.

GRAIN. "Trece años de soja en Argentina: las consecuencias inevitables de un modelo genocida y ecocida". 2009. Consultado el 15 de marzo de 2013. http://www.nodo50.org/ceprid/spip.php?article576\&lang=es

HERKEN KRAUER, Pablo. "Situación de la economía paraguaya". Revista Paraguaya de Sociología no. 131 (2008): 147-58.

INSFRÁN, José Luis. "Enfermedades hematológicas y transgénicos". Acción no. 328 (2012): 12-13.

KALISCH, Hannes. “La Ley de Lenguas y los pueblos indígenas”. Acción no. 321 (2012): 9-11.

KALVODA, Josef. “Communist Strategy in Latin America”. The American Review no. 3 (1961): 5-13.

KONIECKI, Dieter (Ed.). Sistemas electorales y representación política en Latinoamérica. Madrid: Fundación Friedrich Ebert-Instituto de Cooperación Iberoamericana, 1986.

LEZCANO, Carlos María. "El régimen militar de Alfredo Stroessner. Fuerzas Armadas y política en el Paraguay 1954-1989”. Síntesis no. 10 (1990): 167-192. 
LOVERA, Miguel. "Transgénicos en la agricultura: una imposición motivada ideológicamente". Acción no. 328 (2012): 8-11.

MARTÍNEZ ARGUDÍN, Lester. "Importancia geoestratégica del Acuífero Guaraní para América”, 2010. Consultado el 15 de marzo de 2013.

http://www.nodo50.org/ceprid/spip.php?article903\&lang=es

MASI, Fernando. "Rio Tinto Alcan: la complejidad de una inversión" Economía y sociedad no. 4 (2012): 10-16.

MIRANDA, Aníbal (Comp.). Documentos de Fuentes Norteamericanas: EE.UU. y el Régimen Militar Paraguayo. Asunción: El Lector, 1987.

MELO FILHO, Murilo. El desafío brasileño. Buenos Aires: Pomaire, 1972.

MÉNDEZ-FAITH, Teresa. Crónicas y ensayos paraguayos de ayer y de hoy. 2 tomos. Asunción: Intercontinental, 2009.

MORA MÉRIDA, José Luis. Paraguay y Uruguay contemporáneos. Sevilla: Escuela de Estudios Hispano-Americanos de Sevilla, 1981.

MORENO BEAUCHEMIN, Ernesto. Historia del movimiento sindical chileno. Una visión cristiana. Santiago de Chile: Instituto Chileno de Estudios Humanísticos, 1986.

NICKSON, Robert Andrew. "El régimen de Stroessner (1954-1989)". En Historia del Paraguay, editado por Ignacio Telesca. Asunción: Taurus, 2010.

NIEDERGANG, Marcel. Les 20 Amériques latines. 1. Brésil. Argentine. Uruguay. Paraguay. París: Editions du Seuil, 1969.

ORTIZ, Arístides. "Paraguay: Lugo se aleja de los movimientos sociales y de las izquierdas”. 2009. Consultado el 15 de marzo de 2013.

http://www.nodo50.org/ceprid/spip.php?article565\&lang=es

PALAU, Tomas. "La difícil compatibilidad entre las tendencias del comercio exterior y la adecuación monetaria”. Síntesis no. 10 (1990): 311-323.

"Los actores del modelo: gremios y empresarios bien alineados". Acción no. 317 (2011): 15-8.

PASTORE, Carlos. La lucha por la tierra en el Paraguay. Proceso histórico y legislativo. Montevideo: Antequera, 1949.

PECCI, Antonio. “Apuntes acerca del exilio interior y la creciente producción cultural del país”. En Crónicas y ensayos paraguayos de ayer y hoy, tomo II, coordinado por Teresa Méndez-Faith. Asunción: Intercontinental, 2009.

PÉREZ CANTÓ, Pilar y CASAÚS ARZÚ, Marta Elena. (eds.). La mujer latinoamericana ante el reto del siglo XXI. IX Jornadas de Investigación 
Interdisciplinaria sobre la Mujer. Madrid: Universidad Autónoma de Madrid, Instituto Universitario de Estudios de la Mujer, 1993.

RICHER, Hugo. "Seis preguntas y seis respuestas sobre la crisis paraguaya”. 2012.

Consultado el 15 de marzo de 2013.

http://www.nodo50.org/ceprid/spip.php?article1561\&lang=es.

RIQUELME, Quintín. "Lo social en el gobierno Lugo: de la esperanza a la incertidumbre". Acción no. 317 (2011): 19-23.

RIVAROLA, Domingo. (Comp.). Los movimientos sociales en el Paraguay. Asunción: Centro de Estudios Sociológicos, 1986.

"Estado, sociedad civil y proceso educativo". Revista Paraguaya de Sociología no. 131 (2008): 159-182.

“De la soberanía y representación”. Acción no. 317 (2011): 9-11.

RODRÍGUEZ, José Carlos. "Sindicalismo y transición. Paraguay 1989”. Síntesis no. 10 (1990): 249-73.

“ "Querella en la sucesión de Lino O”, en C. Leguizamón (coord.), 2013, 4-6.

ROETT, Riordan. Brazil. Politics in a Patrimonial Society. Westport: Greenwood Publishing Group, 1992.

ROJAS Villagra, Luis. Paraguay. Corporaciones transnacionales y agronegocios. Las Corporaciones Transnacionales en Paraguay (1), 2010. Consultado el 14 de marzo de 2013. http://elpolvorin.over-blog.es/article-paraguay-corporaciones-transnacionales-yagronegocios-luis-rojas-villagra-54708301.html

ROLÓN, Yudith. (coord.). Comisión de Verdad y Justicia. Informe Final. Anive haguã oiko. Algunos casos paradigmáticos. Tomo VII. Asunción: Comisión de Verdad y Justicia, 2008.

RUESGA, Santos M. y Julimar da SILVA BICHARA. Modelos de desarrollo económico en América Latina: desequilibrio externo y concentración de riqueza. Madrid: Marcial Pons, 2005.

RUIZ GARCÍA, Enrique. América Latina, hoy. Anatomía de una revolución. Madrid: Alianza, 1971.

SÁNCHEZ HAASE, Diego. La Música en el Paraguay. Asunción: El Lector, 1998.

Secretaría de Prensa y Difusión. Forjadores de la hermandad argentino-paraguaya. Asunción, 1954. 
SERAFINI GEOGHEGAN, Verónica. "Epidemias de dengue: ¿reflejan la situación del sector público y la ciudadanía paraguaya?”. Economía y sociedad no. 5 (2013): 7-8.

O'SHAUGHNESSY, Hugh. The Priest of Paraguay: Fernando Lugo and the Making of a Nation. Londres: Zed Books, 2009.

SOTO, Clyde. "Desafíos para el feminismo en Paraguay". En La mujer latinoamericana ante el reto del siglo XXI. IX Jornadas de Investigación Interdisciplinaria sobre la Mujer. Editado por PÉREZ CANTÓ, Pilar y Marta Elena CASAÚS ARZÚ. Madrid: Universidad Autónoma de Madrid, Instituto Universitario de Estudios de la Mujer, 1993. STROESSNER, Alfredo. El Coloradismo Paraguayo frente a la Organización Comunista Internacional. Asunción: Imprenta Nacional, 1954.

Mensaje del Excmo. Señor Presidente de la República y Comandante en Jefe de las Fuerzas Armadas de la Nación GENERAL DE EJÉRCITO ALFREDO STROESSNER a los Honorables Miembros del Congreso Nacional. Asunción: Imprenta Nacional, 1973.

TELESCA, Ignacio. (ed.). Historia del Paraguay. Asunción: Taurus, 2010.

VIAL, Alejandro. "El Paraguay en el mundo global: retos, desafíos y oportunidades". Revista Paraguaya de Sociología no. 129-130 (2007): 129-91.

VIANA, Natalia. "Paraguay: Curuguaty, la masacre que derrumbó a Lugo". Sin Permiso no. 30 (2012).

WEY, Walter. La poesía paraguaya. Historia de una incógnita. Montevideo: Alfar, 1951. VAN WYNEN THOMAS, Ann y Archibald J. THOMAS, JR. La Organización de los Estados Americanos. México: 1968. 